\section{TCH-041 STABILITY OF TOTAL PARENTERAL NUTRITION ADMIXTURES FOR PAEDIATRIC HOME CARE IN THE PRESENCE OF HIGH CONCENTRATIONS OF ELECTROLYTES}

doi:10.1136/ejhpharm-2013-000276.232

${ }^{1} \mathrm{D}$ Watrobska-Swietlikowska, ${ }^{2} \mathrm{~A}$ Szlagatys-Sidorkiewicz. ${ }^{1}$ Medical University of Gdansk, Department of Pharmaceutical Technology, Gdansk, Poland; ${ }^{2}$ Medical University of Gdansk, Department of Pediatrics Pediatric Gastroenterology Hepatology and Nutrition, Gdansk, Poland

Background In clinical practise electrolyte enrichment of the parenteral nutrition admixtures is a typical request, especially on the neonatal/paediatric wards. The supplementation of parenteral nutrition with high concentrations of electrolytes is an ongoing problem since the stability of lipid emulsions in nutrition admixtures is reduced by bivalent cations.

Purpose To examine the stability of 48 different paediatric admixtures designed for home parenteral nutrition. The admixtures investigated were characterised by high concentrations of electrolytes (20-61 mmol/1 K+, 9-21 mmol/ $1 \mathrm{Ca}^{2+}, 6-20 \mathrm{mmol} / \mathrm{l} \mathrm{Mg}^{2+}$ ).

Materials and Methods Parenteral pre-admixtures were prepared in two-chamber ethyl-vinyl-acetate bags, where a lipid emulsion was separated from the other components. Parenteral preadmixtures (in two chambers) were stored up to 21 days at $+4^{\circ} \mathrm{C}$. Vitamin preparations were added only after combining the contents of two chambers of the bag.

Visual observations, globule size measurement (optical microscopy, laser diffraction (LD) and photon correlation spectroscopy (PCS)), zeta potential, $\mathrm{pH}$ analysis and surface measurements were performed in complete admixtures at $\mathrm{t}=0$ and after $24 \mathrm{~h}$ at room temperature.

Results In microscopic observation all admixtures were characterised by size of oily droplets not larger than $1 \mu \mathrm{m}$, which was confirmed using LD and PSC methods (Z-average was 260-310 nm). Oily droplet size did not change during the time of storage. Only in two admixtures were single particles up to $8-10 \mu \mathrm{m}$ observed, so these admixtures were classified as unstable. The $\mathrm{pH}$ values of parenteral admixtures were in the range 5.6-6.7 and zeta potential was -36 to $-47 \mathrm{mV}$ and did not change during storage.

Conclusions Of the 48 admixtures investigated only two were problematic and the others may be stored for at least 21 days at $4^{\circ} \mathrm{C}$. The completed admixtures demonstrated stability for at least $24 \mathrm{~h}$ at room temperature. It was possible to obtain stable admixtures despite the high concentrations of electrolytes.

No conflict of interest.

\section{TCH-042 STABILITY STUDY OF GANCICLOVIR IN 0.9\% SODIUM CHLORIDE IN DIFFERENT TYPES OF CONTAINERS: OPTIMIZATION OF RESOURCES}

doi:10.1136/ejhpharm-2013-000276.233

${ }^{1} \mathrm{C}$ Tomasello, ${ }^{1} \mathrm{MM}$ Giacomotti, ${ }^{2} \mathrm{~A}$ D'Avolio, ${ }^{2} \mathrm{M}$ Simiele, ${ }^{3} \mathrm{~A}$ Leggieri, ${ }^{2} \mathrm{G}$ Di Perri. ${ }^{\prime} \mathrm{As}$ To2, Hospital Pharmacy - M. Vittoria, Turin, Italy; '2aboratory of Clinical Pharmacology and Pharmacogenetic Unit of Infectious Diseases University of Turin, Department of Medical Sciences Amedeo di Savoia Hospital, Turin, Italy; ${ }^{3}$ Asl To2, Hospital Pharmacy S.G. Bosco and M. Vittoria, Turin, Italy

Background Ganciclovir is approved for the treatment of cytomegalovirus infections in patients with complications and for its prevention in recipients of solid organ transplants. This drug must be diluted by a hospital pharmacist. To our knowledge, there are no data about ganciclovir stability in two kinds of containers: polyolefin and polyethylene.

Purpose To demonstrate the stability of ganciclovir sodium in $0.9 \%$ sodium chloride in two different types of containers: polyethylene [Ecoflac] and polyolefin [Viaflo]. It is very important to attribute a suitable expiry for this drug, prepared for infected hospital patients, in order to organise the work better and optimise the use of time and resources.

Materials and Methods Twelve admixtures were prepared, six for every concentration $(4.55$ and $0.8 \mathrm{mg} / \mathrm{mL})$, of ganciclovir sodium in $0.9 \%$ sodium chloride, stored at room temperature, at $4^{\circ} \mathrm{C}$ and $-20^{\circ} \mathrm{C}$ (in darkness) in two type of containers, polyethylene and polyolefin. The admixtures were evaluated for up to 21 days at the three temperature conditions. To cheque the concentrations a UPLC-PDA method was developed.

Results The method developed showed no interference peaks, and was reproducible and linear. There was no significant loss of ganciclovir during the study period. The drug at the concentrations considered showed no more than $5 \%$ of degradation during the analysis period in all the storage conditions. Moreover, there were no appreciable $\mathrm{pH}$ changes, and no evidence of visual incompatibility.

Conclusions Ganciclovir sodium $4.55 \mathrm{mg} / \mathrm{mL}$ and $0.8 \mathrm{mg} / \mathrm{mL}$ in $0.9 \%$ sodium chloride in two different kind of bags (Viaflo and Ecoflac $100 \mathrm{~mL}$ ) was visually and chemically stable for at least three weeks when stored at room temperature, $4^{\circ} \mathrm{C}$ and $-20^{\circ} \mathrm{C}$.

No conflict of interest.

\section{TCH-043 STABILITY STUDY OF SILDENAFIL CAPSULES BY HIGH PERFORMANCE LIOUID CHROMATOGRAPHY}

doi:10.1136/ejhpharm-2013-000276.234

M Lebecque, H Beaussart, C Berneron, P Odou. CHRU Lille, Pharmacy, Lille, France

Background Sildenafil, a phosphodiesterase V inhibitor, is used in paediatrics to treat pulmonary arterial hypertension. However no paediatric formulation was available until a recent launch announced a powder for oral suspension.

Purpose To determine the stability of sildenafil capsules for paediatric dilutions. A HPLC assay has been developed for this purpose.

Materials and Methods The sildenafil dosing method, developed from a previously published method1, is a reverse phase HPLC with UV detection at $240 \mathrm{~nm}$. The column is a C18, the mobile phase composition is acetonitrile/ammonium acetate $0.2 \mathrm{M}(50 / 50)$ with a flow set at $1 \mathrm{~mL} / \mathrm{min}$. Linearity and precision cheques (repeatability and intermediate precision) have been performed to validate the method. Capsules of $1 \mathrm{mg}, 5 \mathrm{mg}$ and $10 \mathrm{mg}$ (of sildenafil base) were prepared with sildenafil citrate and corn starch. Samples wer kept at ambient temperature in transparent blister packs sealed with aluminium foil. Uniformity of mass was verified at D0. The visual appearance of the capsules, sildenafil concentrations and chromatographic profiles were checked at D0, D7, D14, D21, D35, D42, D56 and D70.

Results The method was linear up to $150 \mathrm{mg} / \mathrm{mL}$. Repeatability and intermediate precision were demonstrated (SD $<2 \%$ ). Uniformity of mass was verified, no change in visual appearance and no additional chromatographic peaks were observed. The percentages of the remaining concentrations of sildenafil in the capsules compared to initial concentrations were higher than $90 \%$ at D70.

Conclusions The method has been validated and used in a stability study which demonstrated the stability of sildenafil capsules up to ten weeks under the storage conditions studied. These results led us to apply a shelf life of eight weeks to sildenafil capsules.

\section{Reference}

1. Daragmeh N. et al, Determination of sildenafil citrate and related substances in the commercial products and tablet dosage form using HPLC. J Pharm Biomed Anal. 2001;25:483-492

No conflict of interest. 